\title{
Nota sobre dualidad simbólica en Aguada. Un caso de estudio: La túnica hallada en San Pedro de Atacama, Chile
}

\begin{abstract}
RESUMEN
En el registro arqueológico del Noroeste argentino (N.O.A.), es recurrente la presencia de morteros líticos y pipas de cerámica que exhiben representaciones duales. A pesar de que no se han realizado suficientes análisis químicos y botánicos para confirmar la relación de estos implementos con sustancias psicoactivas, se infiere que estos artefactos estarían vinculados con la preparación y el consumo de alucinógenos. En esta nota analizamos la dualidad simbólica y su posible vinculación con el consumo de alucinógenos, a partir de la iconografía exhibida por un textil originario del N.O.A. y hallado en un fardo funerario en San Pedro de Atacama (Chile).
\end{abstract}

Palabras claves: dualismo - textiles - alucinógenos - Aguada.

\section{ABSTRACT}

The presence of lithic mortars and ceramic pipes exhibiting dual representations, is frequent in the archaeological record from Northwestern Argentina (N.O.A.). Although chemical and botanical analysis have not been performed sufficiently to confirm the relation of these implements with psychoactive substances, it is inferred that these artifacts may have been connected with the preparation and consumption of hallucinogens. In this note we analyze symbolic dualism and its possible relation with the consumption of hallucinogens, based on the iconography of a textile from N.O.A. found in a funerary bundle from San Pedro de Atacama (Chile).

Keywords: dualism - textiles - hallucinogens - Aguada.

\section{Introducción}

Existen evidencias que prueban que el dualismo simbólico estuvo ampliamente difundido en la cosmovisión de distintas sociedades que ocuparon, temporal y espacialmente, el "mundo" andino. La iconografía refleja, en los más diversos mate-

1 Instituto de Arqueología y Museo. Facultad de Ciencias Naturales. Universidad Nacional de Tucumán. San Martín 1545, C.P.: 4000, San Miguel de Tucumán, Argentina. Email:vataliva@hotmail.com riales, ejemplos claros y recurrentes de bipartición simbólica, demostrando que no es un arreglo o capricho estético del artesano, que no es casual y tampoco un elemento aislado en la historia de los grupos humanos. Por el contrario, el dualismo está íntimamente relacionado con la cosmovisión de la sociedad que lo manifiesta y tiene una larga data en lugares relacionados con lo ceremonial. Se encuentra ya presente en el 2000 AC en la arquitectura ceremonial del Templo de las Manos Cruzadas (Kotosh) (Burger y Salazar-Burger 1994); se lo ha vinculado con la distribución de ciertos implementos de carácter ceremonial a partir de las posibles relaciones políticas interétnicas durante parte del primer milenio de nuestra era en los Andes Centro-Sur (Berenguer 1993 y 1998) y continúa latente hoy en muchas sociedades andinas, en algunas de las cuales a un dualismo simbólico le corresponde también un dualismo sociológico (Urton 1994). Tres ejemplos que recorren cuatro milenios de historia andina y que reflejan las distintas maneras en las que la bipartición simbólica puede presentarse.

Para las sociedades que se desarrollaron en lo que hoy en día es el Noroeste argentino (N.O.A.), contamos con numerosos ejemplos: en la iconografía registrada en distintos artefactos (por ejemplo, objetos cerámicos y morteros líticos), en el arte rupestre, o bien, en las características formales de los espacios construidos. Los ejemplos que vamos a considerar en este trabajo, se ubican desde el 2000 al 1000 antes del presente, abarcando gran parte del Período Formativo y todo el Período Medio del N.O.A.: tiempo y espacio donde confluyen distintas sociedades con estrategias agrícolas y/o pastoriles plenamente desarrolladas.

A partir del análisis iconográfico expresado en un soporte escasamente conocido en el patrimonio cultural de las sociedades prehispánicas del N.O.A., la textilería, nuestro objetivo es establecer relaciones entre la bipartición simbólica y otro elemento común a numerosas sociedades andinas: el consumo de alucinógenos. Para ello, nos remi- 
tiremos brevemente a los antecedentes de dualismo y elementos relacionados con el consumo de alucinógenos en el N.O.A. para este momento y a las posibles relaciones entre ambos.

\section{El concepto de dualismo}

Consideramos para este trabajo, la definición propuesta por Burger y Salazar-Burger en su análisis sobre dualismo dinámico u oposición dual en sociedades andinas tempranas:

"En el sentido más básico, la realidad se concibe compuesta por fuerzas complementarias que son opuestas. Estas fuerzas no son equivalentes (es decir, son diferentes o asimétricas) pero ambas son necesarias para complementarse y lograr el balance” (1994: 98).

La dualidad puede manifestarse bajo distintas formas, unas se pueden identificar más rápidamente que otras (p.e., cuando existe una marcada diferencia, sea en posición o en atributos iconográficos, entre dos imágenes en un mismo objeto). Entre las más complejas se encuentran las figuras anatrópicas y las de perfil doble, en ambas se cumple el mismo principio, es decir, la existencia de dos imágenes (que representan atributos, fuerzas, etc.) que, según el ángulo de observación o al complementarse las imágenes, forman una sola.

\section{Antecedentes}

Alberto R. González fue el primer investigador que realizó una sistemática descripción y clasificación de las figuras duales y anatrópicas que, procedentes del N.O.A., eran conocidas hasta mediados del '70 (González 1974). El autor las interpretó a partir de la información contextual, etnohistórica y etnográfica disponible, trazando paralelos entre las distintas sociedades prehistóricas del N.O.A. con otras sociedades andinas -principalmente- y amazónicas, entre otras. Postula que

"las fuentes decoradas como los morteros, las pipas y los vasos cilíndricos de esteatita debieron estar relacionados con aspectos rituales $y$ específicamente con el uso de drogas y alucinógenos" (González 1974: 99, destacado en el original).

Si bien existe una variedad importante de objetos donde se registra la bipartición, tienen una mayor importancia -a los fines de este trabajo- aquellos elementos que están relacionados con la preparación y/o consumo de alucinógenos: los morteros y las pipas.

Existen numerosos ejemplares de morteros líticos con figuras talladas, en donde la oposición binaria se presenta bajo distintas formas (González 1974). Recipientes líticos con imágenes anatrópicas que pertenecen a la cultura material de CondorhuasiAlamito han sido analizados por Taboada (1995 Ms), como así también lo que la autora denomina "piezas con doble orientación”, es decir, “...aquellas que presentan dos planos potenciales de observación y/o utilización" (González 1974: 88). Para Núñez Regueiro y Tartusi (1997) estos recipientes líticos del Campo de Pucará estarían relacionados con el consumo de sustancias alucinógenas. Los autores han redefinido los sitios de Alamito como "verdaderos centros ceremoniales" (Tartusi y Núñez Regueiro 1993: 27). Recordemos que González (1974: 92) interpretó las dos plataformas de los sitios de Alamito como ejemplo de bipartición, dualidad arquitectónica que se correlacionaría, según Tartusi y Núñez Regueiro (1993), con una organización bipartita de la sociedad.

Con respecto a las pipas, existen numerosos ejemplares que poseen el hornillo decorado con cuatro caras modeladas, cada par de caras opuestas son idénticas y se diferencian notablemente del otro par. Por ejemplo, a dos caras humanas naturalistas se contraponen otras dos monstruosas o a dos caras humanas se contraponen un par de rostros felínicos. Un ejemplo de este último tipo es un hornillo que pertenece a la colección del Instituto de Arqueología y Museo de la Universidad Nacional de Tucumán. Este ejemplar no se halla completo, carece de una de las fauces felínicas debido a una fractura reciente, pero existía también en ese lado del hornillo (Figura 1). González (1974: fig. 16) ha registrado también, en el hornillo de una pipa acodada, el modelado de una figura anatrópica.

Pero aun cuando es sugerente la relación dualidad-consumo de alucinógenos, resulta difícil asociarlo en forma directa, dado que muchas de las piezas que presentan estas características no poseen un contexto arqueológico definido. Por otra parte, a excepción de los análisis llevados a cabo 


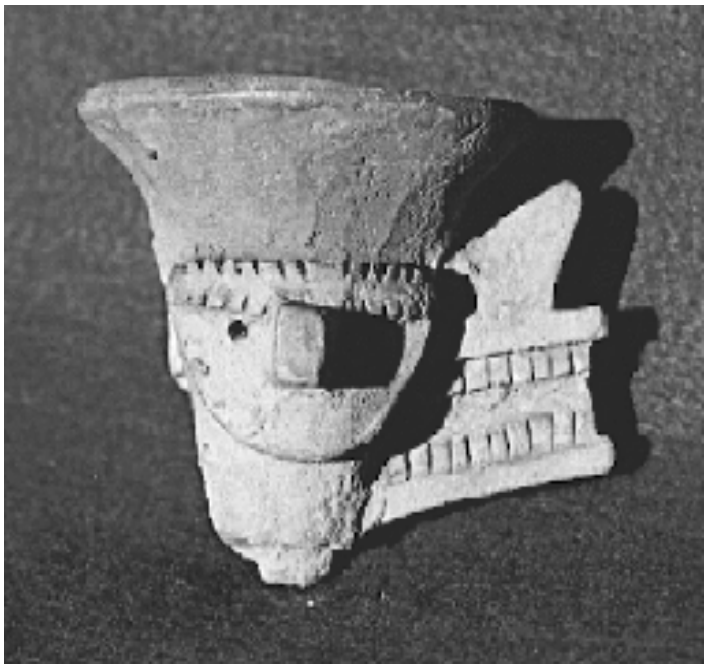

Figura 1. Hornillo de pipa (Colección del I.A.M., Tucumán).

por Fernández Distel (1980) en las pipas de hueso halladas en Inca Cueva 7 y por Pochettino y colaboradores (1999) para momentos anteriores y posteriores al lapso temporal contemplado aquí, no contamos para el N.O.A. con otros análisis de muestras para determinar el contenido de morteros y pipas, y comprobar si efectivamente contenían y se consumían en ellas cebil, tabaco, la mezcla de ambas u otras sustancias psicotrópicas. ${ }^{2}$ En algunos casos, estos análisis no se han llevado a cabo porque el material cultural pertenece a antiguas colecciones de museo o a colecciones privadas (por lo que es previsible la contaminación de la muestra), mientras que en otros casos la muestra es insuficiente o inexistente (ya sea porque se la halló así o por limpieza del material en los museos).

Por último, se ha propuesto, principalmente a partir del análisis del arte rupestre y la abundante presencia de Anadenanthera, a los aleros y grutas ubicados en la Sierra de Ancasti (Catamarca) como espacios ceremoniales relacionados con la iniciación chamánica (De la Fuente 1990) o donde se llevaban a cabo ritos de sacrificios (González 1998). Recordemos que en estos sitios existen imágenes duales, por ejemplo, una imagen bipartita o doble y figuras bicéfalas de felinos con

2 Como ha señalado Pérez Gollán (2000), además de la Anadenanthera, se habría consumido en el N.O.A. prehispánico, chamizo, coro y ashuma. rasgos de llamas y serpientes (De la Fuente y Díaz Romero 1974, Gordillo et al. 2000).

Recapitulando, existen pipas y morteros que presentan claros ejemplos de dualismo simbólico, estos elementos se relacionarían con el consumo de alucinógenos y, tal vez, también con prácticas religiosas íntimamente arraigadas en el seno de distintas sociedades andinas: el chamanismo. Evidentemente, consumo de alucinógenos no implica necesariamente chamanismo, pues éste nos remite a un corpus de conocimientos y prácticas religiosas que si bien en ocasiones pueden ser detectadas arqueológicamente (tal es el caso de algunos elementos de la parafernalia, por ejemplo, pipas y tabletas) en otros casos escapan al registro arqueológico o a nuestras interpretaciones. En otras palabras, la presencia de pipas y morteros no nos indican por sí mismos la práctica del chamanismo (aunque sí, probablemente, consumo de alucinógenos) sino que pueden ser indicios del mismo, ya que asumimos que es en el contexto de producción, circulación y empleo de estos objetos, en donde se legitima y fundamenta la práctica chamánica.

\section{Aguada en San Pedro de Atacama}

La descripción y análisis de las distintas tecnofacturas registradas en San Pedro de Atacama y la adscripción de éstas a Aguada, la debemos a los trabajos de Berenguer (1984) y Llagostera (1995). Tipas, material de madera (keru, figurina, palito lliptero), cerámica y una túnica han sido encontrados en el área atacameña, conservados en muy buen estado por las condiciones ambientales del norte de Chile. La importancia de estos hallazgos, en forma sintética, radica en: a) el incremento del conocimiento sobre la ergología y técnicas de manufactura del Período Medio del N.O.A.; b) reconsideración de hipótesis y planteamiento de otras nuevas, acerca de las relaciones prehistóricas entre el norte de Chile y el N.O.A.; y c) permite el análisis iconográfico sobre soportes poco conocidos del patrimonio cultural de Aguada (p.e., la túnica y las tipas).

\section{La túnica Aguada}

Llagostera (1995) describe una túnica que formaba parte de un fardo funerario del sitio Quitor 2 correspondiente a la momia $\mathrm{n}^{\circ}$ 1983:15 (Conklin y Conklin 1996/97) y que, por la decoración que 
presenta y la técnica empleada para su manufactura, la adscribe a La Aguada. ${ }^{3}$ Para la descripción de la misma, nos servimos de su trabajo:

"Cada lado del unku está dividido en dos campos: uno superior, que ocupa los dos tercios del alto de la pieza y uno inferior que ocupa el tercio restante. El campo superior lleva una figura de un felino sentado, con lunares romboides, tronco arqueado y una gran cola enroscada. El campo inferior porta un ser teratomorfo serpentiforme que tiene una cabeza en cada extremo, cada una de las cuales lleva un penacho sobre la testa y protuberancia ganchuda sobre el hocico. El cuerpo lleva el mismo tipo de lunares que el felino y tanto en el dorso como en el vientre tiene placas triangulares configurando un perfil aserrado (...)" (Llagostera 1995: 20).

Según observan Conklin y Conklin (1996-97: 190), la parte superior de la prenda es azul, y la inferior rojiza, los colores están invertidos en la parte posterior de la túnica.

La pieza, por sus dimensiones, ha llamado la atención de Llagostera (1995) quien, comparándola con las túnicas locales, destaca el reducido tamaño de la túnica foránea. Al respecto, Conklin y Conklin (1996/97) sugieren que por su tamaño (71 cm de largo y $54 \mathrm{~cm}$ de ancho, según los autores) podría haber pertenecido a un niño. Cabe aclarar que el fardo funerario del cual formaba parte, contenía un cuerpo momificado de un hombre de aproximadamente 40 años de edad (Conklin y Conklin 1996/97: 192).

Resulta difícil determinar, a partir del tamaño de la túnica, si perteneció a un niño o a un adulto, mas aun cuando el registro textil de las sociedades prehistóricas del N.O.A. se presenta como fragmentario debido, principalmente, a la mala conservación de esta porción de la cultura material. Observando las figurinas de cerámica que se hallan depositadas en el Instituto de Arqueología y Museo de Tucumán (I.A.M.), e incluso las que se ilustran en algunas publicaciones y que, tipológicamente, son adscritas a Aguada, podemos notar que en muchas de ellas se puede delimitar claramente el tamaño de los textiles que portan.

3 Esta túnica pertenece a la Colección del Museo Arqueológico R. P. Gustavo Le Paige s. j. San Pedro de Atacama.
De hecho, en muchas figurinas se puede distinguir si representan a uno u otro sexo y en ambos casos poseen indumentaria de tamaño reducido. En estas piezas modeladas, aquellas que representan hombres portan túnicas que llegan hasta la cintura de la figurina, o bien se han remarcado los atributos masculinos destacando que la túnica no llegaba más abajo de la pelvis. Algunas figurinas femeninas poseen un textil hasta la cintura y lo que parecería ser un faldellín, otras poseen un único indumento que, desde los hombros, cae hasta las rodillas. En síntesis, las representaciones modeladas sugieren que en el caso de los hombres la túnica llega hasta la cintura y en las mujeres hasta las rodillas, o bien, es de reducidas dimensiones y la pelvis es cubierta por otro tipo de atuendo. Por otra parte, la iconografía de numerosas piezas cerámicas y aun en el arte rupestre, también parece dar indicios de esta tendencia. De todos modos, debemos aclarar que esta observación dista de ser sistemática, por lo que un análisis detallado de esta evidencia indirecta podría arrojar mayor luz en esta u otra dirección. Por lo expuesto, no descartamos la posibilidad de que la túnica en cuestión podría haber pertenecido a un adulto más que a un niño (recordemos también que el fardo contenía un individuo adulto).

A partir de la descripción de esta túnica realizada por Llagostera (1995), realizamos la siguiente interpretación del motivo decorativo de la túnica, iconografía que nos es familiar principalmente a partir de la cerámica (Figura 2).

En la parte superior de la prenda se encuentra un felino, cuyo carácter naturalista contrasta notablemente con la figura inferior. Este felino no parece estar en posición de defensa o ataque, parece estar reposando tranquilamente, no posee el "penacho sobre la testa" ni la "protuberancia ganchuda sobre el hocico" a comparación de las cabezas felínicas que se encuentran en la porción inferior de la túnica. Muestra sus fauces y sus garras, pero no en forma amenazante.

La figura que se encuentra por debajo del felino naturalista, presenta a dos felinos que se unen debido a que las partes caudales de los cuerpos adoptan una forma serpentiforme, dando una impresión de movimiento, a diferencia del felino anterior que parece estar estático. La "protuberancia ganchuda" y el copete sobre la cabeza le confieren a la imagen ferocidad, además las "placas triangulares" que se encuentran "configuran- 


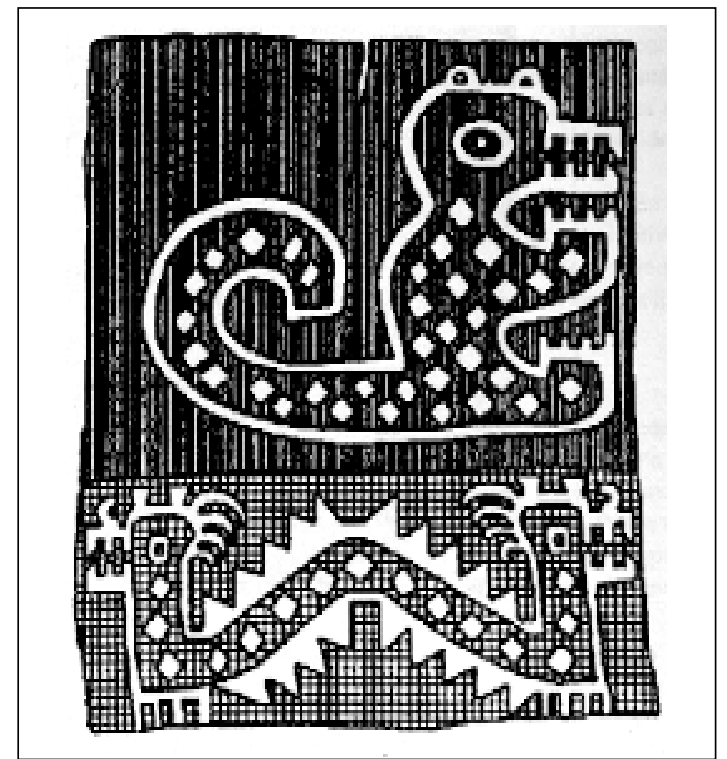

Figura 2. Representación de la túnica Aguada recuperada en San Pedro de Atacama (Tomada de Llagostera 1995).

do un perfil aserrado" colaboran con el carácter agresivo de la figura. Hemos interpretado la figura "teratomorfa serpentiforme" (sensu Llagostera 1995) como felinos unidos, ya que en la iconografía de Aguada existen numerosos ejemplos de esta imagen, expresada tanto en la cerámica como en el arte rupestre. ${ }^{4}$

Sabemos también que los felinos ante una situación de defensa o ataque arquean su cuerpo sobre las cuatro patas, erizando los pelos de manera que aumenta su tamaño e impresiona al agresor o a la víctima. El artesano, tal vez, representó este comportamiento con el "perfil aserrado", el "penacho sobre la testa" y la curvatura del cuerpo de la figura inferior, favoreciendo también la sensación de movimiento.

4 Bedano y colaboradores (1993: figs. 26 y 31) y Gordillo y colaboradores (2000), entre otros. Debemos destacar que existen algunos elementos constituyentes de esta imagen que también se registran en objetos modelados. Tomemos la "protuberancia ganchuda" que posee la figura bicéfala, este rasgo se presenta también en hachas de metal halladas en tumbas en la localidad de La Aguada (González 19614). La prominencia en forma de gancho se encuentra en el extremo superior de la boca del felino, la porción de la boca en las hachas se encuentra bien limitada, por lo que no puede confundirse con los colmillos del animal (González 1961-4: fig. 20 y 1998: fig. 54). Si observamos
El contraste entre las dos figuras es muy llamativo, antagónico. No se trata de una túnica que sólo refleja dos imágenes de alto valor simbólico para Aguada sino que también refleja, a nuestro entender, un aspecto ideológico presente en otras sociedades andinas: la dualidad. La pugna entre lo estático y lo dinámico, lo pacifico y lo agresivo, arriba y abajo, superior e inferior, etc. Recalcando esta oposición iconográfica, los colores también se oponen en ambos lados de la túnica: azul / rojo en el frente, rojo / azul en el dorso. Si recordamos la descripción de la túnica, cada lado posee la iconografía aquí analizada, solamente se invierte el color de fondo. Esto nos lleva a considerar el efecto visual que presenta la misma. En otras palabras, quienes observaban al portador de la túnica no sólo presenciaban un textil con características atípicas -estilística y técnicamentepara San Pedro de Atacama, sino que la función de la túnica parecería ser destacar, desde al ángulo que se la observe, las representaciones y la alternancia de colores, denotando su carácter bipartito y remitiendo a su significado en forma inmediata.

Asociadas a la túnica se hallaron también siete bolsitas textiles, una de las cuales, por el tipo de cierre que presenta, pareciera corresponder a una prenda foránea. ${ }^{5}$ Esta bolsa posee una decoración muy particular: una mitad constituida por líneas en zigzag y la otra mitad, por rectángulos concéntricos. Conklin y Conklin (1996/97: 202) sugieren que “.... tal vez el diseño exprese el dualismo característico del pensamiento del mundo andino."

Aun cuando la túnica no tiene un contexto claramente definido, nos preguntamos acerca de si podría haber sido un elemento constituyente de la parafernalia litúrgica de un chamán. Esta pregun-

el hornillo que reproducimos (Figura 1), en la porción superior de la boca felínica se halla modelada una prominencia que se proyecta hacia delante, dando la misma impresión que la "protuberancia ganchuda" de la figura bicéfala. 5 El carácter foráneo de esta bolsita, ha sido confirmado a partir del hallazgo de una chuspa (dentro de un importante conjunto de textiles) recuperada en un contexto funerario de la Puna Meridional Argentina (Antofagasta de la Sierra, sitio PP9). López Campeny (2001 y en este volumen) ha confrontado la información técnico-estilística que proviene de ambas chuspas, determinando una tradición textil común para dichas piezas, y originarias del N.O.A. 
ta surge no por extensión de la relación Aguada y elementos para el consumo de alucinógenos que se da en San Pedro de Atacama, sino por la clara dualidad simbólica que refleja el textil y porque, como veremos a continuación, en muchas sociedades el indumento cumple un papel fundamental en la actividad del chamán y constituye la manifestación misma de lo sagrado.

\section{El indumento chamánico}

A partir de estudios sobre el fenómeno chamánico -particularmente investigaciones etnográficas y etnohistóricas- se ha podido reconocer la importancia del indumento dentro del conjunto de elementos que son propios del chamán.

El indumento del chamán, afirma Mircea Elíade,

“(...) constituye por sí mismo una hierofanía y una cosmografía religiosa: revela, no sólo la presencia sagrada, sino símbolos cósmicos e itinerarios metapsíquicos. Examinándolo atentamente el indumento revela el sistema del chamanismo con la misma transparencia que las técnicas y los mitos chamánicos” (1996: 130).

La ceremonia que lleva a cabo el chamán no se realiza con la vestimenta cotidiana, sino con aquella consagrada, ya que ésta "...constituye un sistema simbólico casi completo" y al ponérsela o emplear aquellos elementos de su parafernalia, “...rebasa el espacio profano y se prepara para entrar en contacto con el mundo espiritual" (Elíade 1996: 131).

Es decir que, en la parafernalia del chamán, no sólo se destacan los implementos tales como pipas, tabletas, tubos, cucharas y bolsas o cajas para contener sustancias alucinógenas, sino también otros elementos, como la indumentaria y elementos accesorios que incluyen ciertos tipos de atuendos y tocados, plumas, gorros, colgantes, máscaras, instrumentos musicales de viento y percusión, sonajeros, entre otros. Estos elementos en su conjunto permiten al chamán llegar al estado de trance necesario para cumplir con lo que se ha propuesto (p.e., curar a un enfermo, ser mediador entre los humanos y los seres sobrenaturales, etc.).

La iconografía nos brinda información acerca de indumentos, tocados, orejeras, tobilleras y otros, con los que se representa a determinados perso- najes Aguada. Evidentemente los textiles y los adornos corporales han jugado un rol importante para diferenciarse socialmente pero, debido a las condiciones ambientales del N.O.A., poco es lo que sabemos acerca de la vestimenta y el rol de ésta en el ámbito social.

\section{Discusión}

Las distintas tecnofacturas registradas en contextos funerarios de San Pedro de Atacama por Berenguer (1984), Llagostera (1995) y Conklin y Conklin (1996/97), nos permiten acercarnos a las relaciones interétnicas trasandinas dentro del período comprendido entre los siglos VI y X de nuestra era. ${ }^{6}$ No podemos limitarnos solamente a mencionar la existencia de tal interacción, sino que es relevante analizar el marco social en el que se sustentarían dichas relaciones. Como ya mencionáramos, además de la túnica y la pequeña chuspa con decoración bipartita del fardo funerario, otros artefactos de madera (estatuilla, keru y palito lliptero), de cerámica y tipas fueron recuperados en enterratorios de San Pedro de Atacama. Aparentemente, el registro de estas tecnofacturas se limitaría, principalmente, a tumbas y la circulación de los mismos estaría restringida a cierto sector de la sociedad atacameña.

En efecto, un gran porcentaje de los artefactos ajenos a la tradición atacameña durante el período comprendido entre el 500 y el 1000-1100 DC, estarían vinculados con las relaciones interétnicas establecidas entre las élites locales y entre éstas con otras sociedades, por ejemplo, las altiplánicas de Tiwanaku y las trasandinas del N.O.A. (Berenguer 1993 y 1998, Llagostera 1995). De hecho, en las tumbas en las que se presentan artefactos Aguada, Llagostera (1995) detecta que todos los hombres poseen como ajuar funerario algún implemento para el consumo de alucinógenos, por lo que estos individuos estarían adscritos a la esfera chamánica e, inmediatamente después, nos advierte de que tal situación

\footnotetext{
6 Si bien las relaciones se remontarían a ca. $10.000 \mathrm{AP}$ (Aschero 1998), es recién con el proceso de sedentarización de las sociedades que ocuparon ambas vertientes, que la interacción trasandina se intensifica (Núñez y Dillehay 1995, Tarragó 1989) o, por lo menos, se hace más "tangible" en el registro arqueológico.
} 
“(...) de ninguna manera debe entenderse como una relación entre Aguada y chamanismo, sino que obliga a ubicarnos frente a una problemática mayor que conjuga chamanismo, poder (estatus) y objetos foráneos" (Llagostera 1995: 28).

El alto componente chamánico de la sociedad atacameña ya ha sido destacado por distintos investigadores (Berenguer 1993 y 1998, Llagostera 1995, Llagostera et al. 1988, Torres 1998, entre otros) y se ha comprobado efectivamente el consumo de Anadenanthera colubrina var. cebil (Torres et al. 1991), como así también se registró la presencia de otros elementos originarios del N.O.A., hallados en contextos funerarios, como el gastrópodo Sthrophocheilus que, en ocasiones, se presenta en asociación con algún implemento para el consumo de alucinógenos (Téllez 1997).

Consideramos que los objetos foráneos registrados en este momento pueden ser entendidos en términos del capital simbólico (sensu Bourdieu 2001) que poseían las élites atacameñas, a través del cual establecían y sustentaban las diferencias con el resto de la sociedad y entre ellas mismas. La interacción no sólo permitía el acceso y manipulación de bienes de prestigio y/o recursos producidos y/o generados en lugares distantes, sino que precisamente la tenencia, exhibición y el valor simbólico de los mismos, es lo que fundamentaba la distinción.

En este contexto ¿podemos asignar una función a la túnica Aguada? o, en otras palabras, ¿podemos responder a nuestra pregunta sobre si la túnica constituiría parte de la parafernalia chamánica? Planteamos, a continuación, dos posibles caminos para responder a estas preguntas.

El primero, se refiere al hecho de que si la sociedad que expresa la dualidad concibe ya sea a sus deidades o al cosmos según la oposición y complementariedad entre las fuerzas que lo componen, es probable que este sistema simbólico quede expresado en aquellos elementos empleados por quienes manipulan lo sagrado y detentan el poder dentro de la sociedad, es decir, los chamanes. Entendemos que la dualidad es un atributo de la parafernalia del chamán, por cuanto es atributo de lo sagrado. Esto no quiere decir que cualquier elemento que refleje la bipartición simbólica deba ser adscrito a prácticas chamánicas pero, insistimos, hay ciertos elementos relacionados con el ceremonial (pipas, tubos, tabletas, morteros, vestimenta, entre otros) que sólo el chamán emplea, justamente por su capacidad de manipular lo sagrado y comunicarse, a través de éstos, con lo sobrenatural.

El segundo, constituye una reflexión más que una respuesta: difícilmente podemos responder a estas preguntas a partir de un universo de estudio tan limitado pues nos referimos, en el transcurso de esta nota, a sólo una túnica. Por otra parte, hemos tratado de evitar trazar una relación directa entre consumo de alucinógenos y chamanismo ya que, en general, se ha asumido que uno implica inexorablemente el otro. En el fardo funerario que contenía esta túnica no se registraron implementos para el consumo. Pero si llevamos el fardo a un contexto general, en el cual algunas tecnofacturas del N.O.A. se presentan, en San Pedro de Atacama, vinculadas con algún elemento para el consumo de alucinógenos, la túnica adquiere otro significado, más aún si sumamos el hecho de que, en el N.O.A., elementos relacionados con el consumo o preparación de alucinógenos (las pipas y los morteros) contienen claros ejemplos de bipartición simbólica, como lo presenta la túnica aquí analizada.

En San Pedro de Atacama, y como ya lo han señalado distintas investigaciones, es recurrente la relación entre implementos para el consumo de alucinógenos y artefactos foráneos. Indagar sobre este punto nos remite a diversos aspectos de las interacciones entre la sociedad atacameña y otras sociedades surandinas, tales como las prácticas caravaneras, el acceso diferencial a bienes de prestigio, las alianzas interétnicas, etc. Esta nota constituye una aproximación a sólo un aspecto de las sociedades andinas, pero que invade y se funde en y con los demás, los alucinógenos.

Agradecimiento A Carole Sinclaire por la lectura, correcciones y sugerencias a una anterior versión de esta nota, aunque todo lo expresado aquí es de mi absoluta responsabilidad. 


\section{REFERENCIAS CITADAS}

ASCHERO, C., 1998. Arte y arqueología: Una visión desde la Puna Argentina. Chungara 28 (1 y 2): 175-197, Arica.

BEDANO, M. C., M. S. JUEZ y M. D. ROCA, 1993. Análisis del material arqueológico de la Colección Rosso procedente del Departamento de Ambato, Provincia de Catamarca. Publicaciones del Instituto de Arqueología 7, Universidad Nacional de Tucumán, Tucumán.

BERENGUER, J., 1984. Hallazgos de La Aguada en San Pedro de Atacama, Norte de Chile. Gaceta Arqueológica Andina 12: 12-14, Lima.

-1993. Gorros, identidad e interacción en el desierto chileno antes y después del colapso de Tiwanaku. En Identidad y prestigio en los Andes. Gorros, turbantes y diademas, pp. 41-64. Museo Chileno de Arte Precolombino, Santiago.

-1998. La iconografía del poder en Tiwanaku y su rol en la integración de zonas de frontera. Boletín del Museo Chileno Arte Precolombino 7: 19-37, Santiago.

BOURDIEU, P., 2001. Intelectuales, política y poder. Eudeba, U.B.A., Buenos Aires.

BURGUER, R. y L. SALAZAR-BURGUER, 1994. La organización dual en el ceremonialismo andino temprano: Un repaso comparativo. En El mundo ceremonial andino, L. Millones y G. Onuki (Comps.), pp. 97-116. Editorial Horizonte, Lima.

CONKLIN, W. J. y B. M. CONKLIN, 1996-97. Un textil Aguada en contexto atacameño. Cuadernos del Instituto Nacional de Antropología y Pensamiento Latinoamericano 17: 187-203, Buenos Aires.

DE LA FUENTE, N., 1990. Nuevas pinturas en la ladera oriental de la Sierra de Ancasti, Catamarca. Revista del Centro de Estudios de Regiones Secas, Tomo VII, Tucumán - Catamarca.

DE LA FUENTE, N. y A. DIAZ ROMERO, 1974. Un conjunto de figuras antropomorfas del yacimiento La Tunita, Provincia de Catamarca. Revista del Instituto de Antropología, Tomo V, Universidad Nacional de Córdoba, Córdoba.

ELIADE, M., 1996. El chamanismo y las técnicas arcaicas del éxtasis. F.C.E., México.

FERNANDEZ DISTEL, A., 1980. Hallazgo de pipas en complejos precerámicos del borde de la Puna Jujeña (República Argentina) y el empleo de alucinógenos por parte de las mismas culturas. Estudios Arqueológicos, pp. 5579, Antofagasta.

GONZALEZ, A.R. 1961-4. La Cultura de La Aguada del N.O. Argentino. Revista del Instituto de Antropología, Facultad de Filosofía y Humanidades, Tomo II y III: 205-253, Universidad Nacional de Córdoba, Córdoba.
- 1974. Arte, estructura y arqueología. Fichas $N^{\circ} 35$. Editorial Nueva Visión, Buenos Aires.

- 1998. Cultura La Aguada. Arqueología y diseño. Filmediciones Valero, Buenos Aires.

GORDILLO, I., M. BALDINI y M. F. KUSCH, 2000. Entre objetos, rocas y cuevas: Significado y relaciones entre la iconografía rupestre y mobiliar de Aguada. En Arte en las Rocas. Arte rupestre, menhires y piedras de colores en Argentina, M. M. Podestá y M. de Hoyos (Eds.), pp. 101-112. S.A.A. y A.I.N.A., Buenos Aires.

LOPEZ CAMPENY, S. M. L., 2001. La trama del desierto. Textiles tempranos de Antofagasta de la Sierra (Puna Meridional Argentina). Actas de la XV Reunión Anual del Comité Nacional de Conservación Textil, San Pedro de Atacama. En prensa.

LLAGOSTERA, A., 1995. El componente cultural Aguada en San Pedro de Atacama. Boletín del Museo Chileno Arte Precolombino 6: 9-34, Santiago.

LLAGOSTERA, A., C. M. TORRES y M. A. COSTA J., 1988. El complejo psicotrópico en Solcor - 3 (San Pedro de Atacama). Estudios Atacameños 9: 61-98, San Pedro de Atacama.

NUÑEZ, L. y T. DILLEHAY, 1995. Movilidad giratoria, armonía social y desarrollo en los Andes Meridionales: Patrones de tráfico e interacción económica. $2^{\text {a }}$ Edición. Universidad Católica del Norte, Antofagasta.

NUÑEZ REGUEIRO, V. y M. TARTUSI, 1997. Análisis de la problemática del estudio de las sociedades agropastoriles del Area Centro-Sur Andina. Actas del XII Congreso Nacional de Arqueología I: 107-112. U.N.L.P., La Plata 1999.

PEREZ GOLLAN, J. A., 2000. El jaguar en llamas (La religión en el antiguo Noroeste argentino). En Nueva Historia Argentina, Tomo I, Los pueblos originarios y la conquista, M. N. Tarragó (Dir.), pp. 229-256. Editorial Sudamericana, Buenos Aires.

POCHETTINO, M. L., A. R. CORTELLA y M. RUIZ, 1999. Hallucinogenic snuff from Northwestern Argentina: Microscopical identification of Anadenanthera colubrina var. cebil (Fabaceae) in powdered archeological material. Economic Botany 53 (2): 127-132. The New York Botanical Garden Press, Bronx.

TABOADA, C., 1995 Ms. La escultórica lítica y el trabajo en piedra picada y pulida en Condorhuasi-Alamito. Trabajo Final de la Carrera de Arqueología. Facultad de Ciencias Naturales e Instituto Miguel Lillo, Universidad Nacional de Tucumán, Tucumán.

TARRAGO, M., 1989. Contribución al conocimiento arqueológico de las poblaciones de los oasis de San Pedro de Atacama en relación con los otros pueblos puneños, en 


\section{NOTA SOBRE DUALIDAD SIMBOLICA EN AGUADA}

especial, el sector septentrional del Valle Calchaquí. Tesis para optar al título de Doctor en Historia. Facultad de Humanidades y Artes. Universidad Nacional de Rosario, Rosario.

TARTUSI, M. y V. NUÑEZ REGUEIRO, 1993. Los centros ceremoniales del N.O. argentino. Publicaciones del Instituto de Arqueología 5, Universidad Nacional de Tucumán, Tucumán.

TELLEZ C., F., 1997. Sthrophocheilus oblongus Müll: Restos de fauna malacológica tropical en contextos funerarios de San Pedro de Atacama; norte de Chile (Informe preliminar). Estudios Atacameños 14: 95-120, San Pedro de Atacama.
TORRES, C. M., 1998. Psychoactive substances in the archaeology of Northern Chile and NW Argentina. A comparative review of the evidence. Chungara 30: 4963, Arica.

TORRES, C. M., D. B. REPKE, K. CHAN, D. MCKENNA, A. LLAGOSTERA R. E. SCHULTES, 1991. Snuff powders from pre-hispanic San Pedro de Atacama: Chemical and contextual analysis. Current Anthropology 32 (5): 640-649.

URTON, G., 1994. Actividad ceremonial y división en mitades en el mundo andino. Las batallas rituales en los carnavales del sur de Perú. En El mundo ceremonial andino, L. Millones y G. Onuki (Comps.), pp. 117-142. Editorial Horizonte, Lima. 